\title{
Biomedical and Health Informatics Education and Research at the Information Technology Institute in Egypt
}

\author{
R. Hussein, A. Khalifa \\ Information Technology Institute (ITI), Ministry of Communications and Information Technology (MCIT), \\ Cairo, Egypt
}

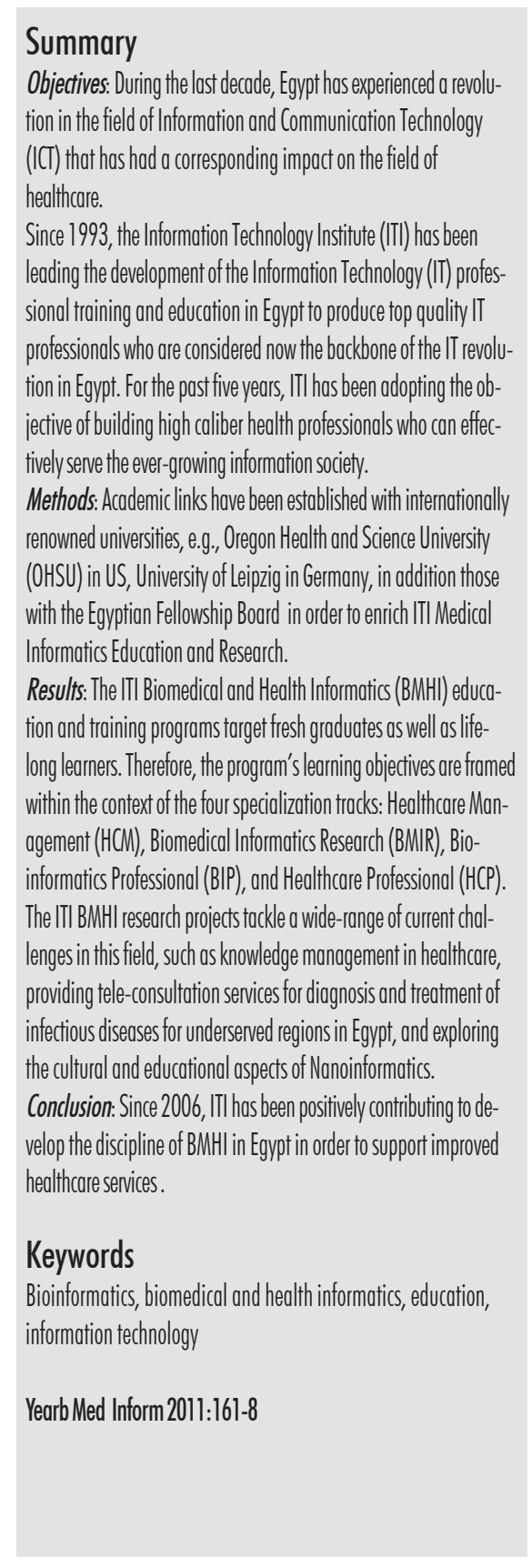

\section{Introduction}

Biomedical Informatics (BMI) is considered to be one of the fundamental disciplines for this century [1]. BMI encompasses the related fields of Bioinformatics, Imaging Informatics, Clinical Informatics (sometimes called 'Medical Informatics', or alternatively 'Health Informatics' in some countries like the UK), and Public Health Informatics.

In 2006, the World Health Organization (WHO) reported that most of the required actions to promote an enabling environment for Information and Communications Technology (ICT) in the Egyptian health sector were being taken [2]. This was mainly achieved by the Egyptian Ministry of Communications and Information Technology (MCIT) as reflected in the MCIT strategy for building the information society [3]. Particularly, MCIT and the Egyptian Ministry of Health $(\mathrm{MoH})$ signed a protocol of cooperation to equip the national health sector with ICT tools to improve quality of service.

However, the WHO reported that there was a strong need for orientation on both eHealth and eLearning technologies in addition to training in the development and management of eHealth systems [2]. Accordingly, the Information Technology Institute (ITI), the training arm of MCIT, took the lead to implement the MCIT strategy for capacity building in different ICT sectors, including the healthcare sector [3].

The main aim of this paper is to highlight ITI activities and contribution in developing the Biomedical and Health Informatics (BMHI) discipline in
Egypt. These activities consist mainly in establishing BMHI education, training and research programs.

\section{Background}

\subsection{Information Technology Institute (ITI)}

The Information Technology Institute (ITI: http://www.iti.gov.eg) is a national, not-for-profit, institute established in 1993. ITI is positioned since 2005 under the umbrella Ministry of Communications and Information Technology (MCIT). For nearly two decades, the institute has been a pioneer in enriching the IT industry by adopting world trends in the ICT domain and introducing them to the Egyptian ICT Industry as highly qualified calibers through its branded 9Month Professional Training Program. This program covers several platforms that relate to the latest industry applications such as: System Development (SD), UNIX, Java, Enterprise Resource Planning (ERP), Quality Assurance (QA), Technologies for Ebusiness, Open Source Technologies, Information Storage Management, Computer Networks, Cyber Security, eLearning Technologies, Mechatronics, Embedded Systems, Multimedia, and Geographical Information Systems (GIS). These platforms are annually updated to include new disciplines designed to match international trends in the field of ICT and to respond to market needs.

The 9-Month Program currently runs at the five ITI branches located in differ 
ent locations ( $6^{\text {th }}$ of October, Cairo, Alexandria, Mansoura, and Assuit). ITI has gained wide national, regional and international recognition, resulting in many successful cooperations with national and international organizations.

\subsection{The International Medical Informatics Association (IMIA) Strategic Plan}

The International Medical Informatics Association (IMIA) is the professional world organization for the BMHI. The importance of the BMHI discipline is strongly highlighted in the Strategic Plan (2008- 2015) of the IMIA "Towards IMIA 2015" [4]. This plan comprises six sectors for Health Vision, Research/Science, Behavioural Responsibility (ethics), Education, Relationships, and Connectivity.

Particularly, the IMIA Health and Medical Informatics Education Group developed (and continuously updates) a set of international recommendations for BMHI education programs and courses. The initial version of these recommendations was published in 2000 and the first revised version was issued in 2010 [5]. The recommendations provide guidance for developing BMHI education at all academic levels.

\section{Rationale for Developing BMHI Education and Research at ITI}

\subsection{At the Regional Level}

In 2001, the Eastern Mediterranean Regional Office (EMRO)-WHO issued a technical paper on health and medical informatics stressing on the role of Health and Medical Informatics as essential tools for health information systems and management [6]. Furthermore, the Regional Committee for the EMRO recommended the importance of developing a regional plan for sys- tematic and institutional implementation of health and medical informatics in the region; initiating a model for medical informatics curriculum, and developing a model for electronic medical record system.

\subsection{At the National Level}

The recent WHO eHealth Country Profile [7] reported that Egypt positively responded to the eHealth foundation actions including: supportive eHealth policy, legal and ethical frameworks, adequate funding from various resources and infrastructure development. However, there was no consolidated data on developing the capacity of the health workforce through training. Furthermore, there was a strong need to different eHealth applications mainly, Telemedicine, mHealth, and eLearning.

At the academic level, there was only one program in BMHI, namely, a Medical Informatics and Bioinformatics Master Program (MIMP) introduced by Helwan, Ain Shams and Suez Canal Universities in Egypt. This program was established through a joint project funded by the TEMPUS Program in 2004 [8]. MIMP targets both healthcare professionals and non-healthcare professionals to gain a theoretical knowledge as well as practical experience in Medical Informatics. Accordingly, the graduates can efficiently manage information within various healthcare systems. The program was launched in 2006 as a 36 credit hours program to acquire a master degree [9].

Consequently, since 2006, one of the main aims of ITI is not only promoting the culture of BMHI literacy but also creating an infrastructure of highly qualified healthcare professionals who are capable of designing and implementing competent systems involved in the healthcare process. Being one of the IMIA's Academic Institutional members since 2007, ITI adopts the IMIA's recommendations on BMHI education to ensure the highest quality and best practices of all ITI BMHI training programs.

\section{ITI BMHI Education and Training Tracks}

The main goal of ITI BMHI education and training programs is to target all types of health professionals in Egypt: policymakers, health providers, physicians, clinicians, nurses, and administrative staff.

Based on the above, ITI designed four different tracks for BMHI education and training:

1. Healthcare Management (HCM) Track: Provides healthcare business and management concepts for the hospital managers, heads of the clinical departments, and directors of health information systems.

2. Biomedical Informatics Research (BMIR) Track: Provides fundamentals of Biomedical Informatics; programming concepts in addition to statistics and quantitative \& qualitative methods for system developers and researchers.

3. Bioinformatics Professional (BIP) Track: Provides bioinformatics fundamentals for non-clinicians.

4. Healthcare Professional (HCP) Track: Provides core courses in health informatics and healthcare applications for physicians, clinicians, nurses, and hospital clerks.

These tracks are implemented in four different BMHI education and training programs as summarized in Table 1 . The curricula of these programs are designed in light of the IMIA recommendations on education in BMHI [5].

The final results of actually applying these programs are summarized in Table 2, emphasizing the graduates' profile for each track specifying the total number of trainees, their competences, job profiles and workplaces.

\subsection{HCM Track - Health Informatics Training Program}

In 2006, ITI jointly with the Faculty of Medicine - Kasr El Ainy Hospital- Cairo University concluded an agreement 
protocol aiming to familiarize the future physician as well as the other allied healthcare specialties with the applications of computing and information systems in health and medicine. The main objective of the Health Informatics Training Program is to fulfill the roles of the healthcare stakeholders working at Kasr El Ainy Hospital as life-long learners, clinicians, educators, communicators, researchers, and managers.

Through this 3-4 month program, the candidates have to pass through three consecutive core modules as follows:
1. Information Technology (IT) Module: This module is designed to give to healthcare professionals the basic concepts of information technology. The case studies and projects associated with the courses are adapted to the IT applications in healthcare. The

Table 1 ITI BMHI education and training programs- summary matrix

\begin{tabular}{|c|c|c|c|c|}
\hline & $\begin{array}{l}\text { Healthcare Management } \\
\text { (HCM) Track }\end{array}$ & $\begin{array}{l}\text { Biomedical Informatics Research } \\
\text { (BMIR) Track }\end{array}$ & $\begin{array}{l}\text { Bioinformatics Professional } \\
\text { (BIP) Track }\end{array}$ & $\begin{array}{l}\text { Healthcare Professional } \\
\text { (HCP) Track }\end{array}$ \\
\hline Program & $\begin{array}{c}\text { Health Informatics Training } \\
\underline{\text { Program }}\end{array}$ & $\frac{\text { ITI/OHSU BMI Professional Training }}{\underline{\text { Program }}}$ & $\frac{\text { Bioinformatics Professional }}{\text { Iraining Program }}$ & $\frac{\text { MoH/ITI Health Informatics }}{\underline{\text { Fellowship }}}$ \\
\hline Duration & $\begin{array}{l}\text { 3-Month } \\
3 \text { Days/Week (200 hrs) }\end{array}$ & $\begin{array}{l}\text { 9-Month } \\
\text { Full-Time }\end{array}$ & $\begin{array}{l}\text { 9-Month } \\
\text { Full-Time }\end{array}$ & $\begin{array}{l}\text { 2-Year } \\
\text { Part-Time } 2 \text { Days/ week }\end{array}$ \\
\hline Training Provider & $\mid \mathrm{TI}$ & ITI/OHSU & ITI & $\mathrm{MoH} / \mathrm{ITI}$ \\
\hline Candidates & $\begin{array}{l}\text { Healthcare Professionals (Kasr } \\
\text { El Ainy Hospital, Cairo University) } \\
\text { "Life-long Learners" }\end{array}$ & $\begin{array}{l}\text { Pharmacists, Dentists, Physicians, } \\
\text { Biomedical Engineers } \\
\text { "Fresh Graduates" }\end{array}$ & $\begin{array}{l}\text { Pharmacists, Biotechnology } \\
\text { Engineers, Chemists, Biologists } \\
\text { "Fresh Graduates" }\end{array}$ & $\begin{array}{l}\text { Healthcare Professionals } \\
\text { (Ministry of Health) } \\
\text { "Life-Long Learners" }\end{array}$ \\
\hline Teaching Language & English/Arabic & English & English/Arabic & English/Arabic \\
\hline Teaching mode & Face-to-Face & Blended Learning & Face-to-Face & $\begin{array}{l}\text { Face-to-Face } \\
\text { Blended Learning (2011) }\end{array}$ \\
\hline Courses & $\begin{array}{l}\text { IT Courses } \\
\text { Healthcare Management }\end{array}$ & $\begin{array}{l}\text { OHSU (Distance Learning) ITI Java } \\
\text { Platform/ } \\
\text { Bioinformatics Platform }\end{array}$ & $\begin{array}{l}\text { IT Courses } \\
\text { Bioinformatics } \\
\text { (Specialized Courses) }\end{array}$ & $\begin{array}{l}\text { Health Informatics } \\
\text { (Specialized Courses) }\end{array}$ \\
\hline Location & ITI/ Kasr El Ainy Hospital & ITI & ITI Smart Village/ITI Assuit & $\mathrm{ITV} / \mathrm{MoH}$ \\
\hline Starting Date & 2006 & Since 2007 & Since 2008 & May 2010 \\
\hline
\end{tabular}

Table 2 ITI BMHI education and training programs- graduates' profile

\begin{tabular}{|c|c|c|c|c|}
\hline & $\begin{array}{l}\text { Healthcare Management } \\
\text { (HCM) Track }\end{array}$ & $\begin{array}{l}\text { Biomedical Informatics Research } \\
\text { (BMIR) Track }\end{array}$ & $\begin{array}{l}\text { Bioinformatics Professional } \\
\text { (BIP) Track }\end{array}$ & $\begin{array}{c}\text { Healthcare Professional (HCP) } \\
\text { Track }\end{array}$ \\
\hline Program & $\frac{\text { Health Informatics Training }}{\text { Program }}$ & $\frac{\text { IT/OHSU BMI Professional Training }}{\underline{\text { Program }}}$ & $\frac{\text { Bioinformatics Professional }}{\text { Training Program }}$ & $\frac{\text { MoH/TII Health Informatics }}{\text { Fellowship }}$ \\
\hline Certificate & ITI Cerrificate & OHSU Graduate Cerrificate in BMI & ITI Diploma & $\begin{array}{l}\text { Fellowship Certificate in Health } \\
\text { Informatics }\end{array}$ \\
\hline Total no. of Trainees & 20 & 29 & 38 & 78 \\
\hline No. of Certified Trainees & 20 & 15 & 29 & In progress \\
\hline Competencies & $\begin{array}{l}\text { Focused knowledge on IT in } \\
\text { addition to the BMHII business } \\
\text { and management aspects }\end{array}$ & $\begin{array}{l}\text { Professional knowledge and ability in } \\
\text { systems development in healthcare in } \\
\text { addition to the fundamental aspects of } \\
\text { scientific research and quantitative } \\
\text { methods in medicine }\end{array}$ & $\begin{array}{l}\text { Better understanding of the human } \\
\text { body in health and disease in } \\
\text { addition to the operations of the } \\
\text { healthcare system }\end{array}$ & $\begin{array}{l}\text { Detailed knowledge on the role of } \\
\text { computer systems and information } \\
\text { technology in healthcare }\end{array}$ \\
\hline Job Profile & - Informatics Training Director & $\begin{array}{l}\text { - BMHI Teaching and Research Assistant } \\
\text { - BMHI Training Director } \\
\text { - Clinical Systems Analyst }\end{array}$ & $\begin{array}{l}\text { - Bioinformatics Teaching and } \\
\text { Research Assistant }\end{array}$ & - Health Informatician \\
\hline Workplace & $\begin{array}{l}\text { - Hospitals } \\
\text { - } \mathrm{MoH}\end{array}$ & $\begin{array}{l}\text { - MCIT/MoH (eHealth Programs and } \\
\text { Initiatives) } \\
\text { - eHealth Industry }\end{array}$ & $\begin{array}{l}\text { - Research Centers } \\
\text { - Freelancers }\end{array}$ & - MoHfacilities \\
\hline
\end{tabular}


164

Hussein et al. courses included are: Computer Network Basics; Database Fundamentals; Introduction to different Operating Systems; and Introduction to Hardware.

2. Healthcare Management Module:

This Module is designed to provide the knowledge of healthcare management from its various aspects. These aspects include the core foundation of the healthcare industry as a whole starting from the policies and ethics of the medical field and ending with the manipulation of information till the decision making phase. The courses included are: Introduction to Healthcare Informatics; Electronic Patient Record; Clinical Decision Support; Medical Statistics; Health-care Policy and Ethics; Clinical and Social Issues in Healthcare; Healthcare and Public Health; Healthcare Systems Planning; and Health Information and Security Issues.

3. Healthcare Management Applications Module: This Module explores different case studies and actual management systems that provide knowledge of real and implemented systems. The courses included are: Hospital Management Systems; and Healthcare Case Studies \& Projects. This is in addition to add-on courses that are designed according to the needs of each healthcare department or specialization, e.g., Healthcare Financing Issues; Marketing Issues; Project Management; Quality Assurance; and Image Processing.

\subsection{BMIR Track - ITI/OHSU BMI Professional Training Program}

ITI in partnership with Oregon Health and Science University-Department of Medical Informatics and Clinical Epidemiology (OHSU-DMICE) offers Graduate Certificate in Biomedical Informatics Program since 2007. This program provides education in the theory and practice of biomedical informatics and targets the fresh distinguished graduates from pharmacists, physicians, dentists and biomedical engineers.

The ITI/OHSU joint Professional Training Program in BMI is a Blended
Learning Program that provides OHSU Graduate Certificate in Biomedical Informatics. This program is not about learning to use a particular technology or a set of applications, but about mastering a body of knowledge about the problems of healthcare, the concepts used in analyzing them and the principles that govern the successful engineering and application of solutions. The program is academically demanding, but rooted in the practical problems of healthcare and involves direct contact with clinical work.

The program, like the other tracks of the 9-Month Professional Training Program, consists of three consecutive modules; each is $3=$ month duration. ITI provides the IT fundamental and specialized courses 'face to face'. Concurrently, OHSU-DMICE provides four specialized courses in Biomedical Informatics through eLearning environment.

ITI-Modules:

1. Foundation Module: This module covers the fundamental courses in IT such as: Database Systems, Computer Networks Fundamentals, Operating System Fundamentals, Windows Operating System, Unix Operating System, Data Structures and Algorithms, C Programming Language, Object Oriented Paradigm in addition to Soft Skills courses.

2. Focus Module: In this module, the students can take the courses of either the Java Platform or the Bioinformatics Platform.

a. Java Platform Courses: Java Programming; Advanced Java Programming; Object Oriented Analysis and Design Using UML; XML and Java API for XML Processing; Servlets and JSP; Jakarta Struts; Java Micro Edition; Linux Administration; in addition to the Practicum.

b. Bioinformatics Platform Courses: Perl Scripting; Bio-Perl; Java Programming; Advanced Java Programming; Bioinfor-matics and Computational Biology Algorithms; Biostatistics; Statistical Bioinformatics; Structure and Function of Biological Molecules; Readings in Bioinformatics; Re- search in Bioinformatics and Computational Biology; in addition to the Practicum.

3. Performance Module: In this module all students undertake a major graduation project as a part of the program. This also includes field visits for healthcare facilities to analyze to which extent the implemented information systems are developed in accordance to the BMHI standards and guidelines. Consequently, the students provide individual/group reports about their findings and recommendations to enhance information processing and workflow across the selected healthcare facilities.

Concurrently with the ITI Modules, OHSU-DMICE offers four online courses in Biomedical Informatics. Three of these courses are mandatory, namely, Introduction to Bioinformatics, Clinical Information Systems, and Organizational Behavior and Management. The fourth course is an elective course that can be selected from this OHSU-DMICE course-list: Information Retrieval \& Digital Libraries; Ethical, Legal and Social Issues in Medical Informatics; Project Management; The Business of Health Informatics, Consumer Health Informatics; Public Health Informatics; Healthcare Quality; Medical Decision Making; or Design and Evaluation in Health Informatics.

\subsection{BIP Track - Bioinformatics Professional Training Program}

The Bioinformatics Professional Training Program was established since 2008 to provide knowledge and practice of both bioinformatics concepts and cutting edge technologies. Through this program, the synergy of integrating biological sciences and information technologies is explored in order to face new challenges in biological sciences.

Aligning with structure of the ITI 9-Month Professional Training Program, Bioinformatics students should pass through three consecutive modules as follows: 
1. Foundation Module: This module covers the fundamental courses in IT such as Operating Systems; Software Engineering; Programming languages $(\mathrm{C}, \mathrm{C}++)$; Networks and Databases in addition to Soft Skills courses.

2. Focus Module: This module provides the vertical coverage of Bioinformatics domain; by investigating through Computational Biology Algorithms; Genetic Mechanisms; Structure and Function of Biological Molecules; Bio-Perl and its applications; Data Mining; Bio-Statistics; Drug design; Proteomics; and Mathematical \& Computational Modeling of Biological Systems.

3. Performance Module: In this module all students undertake a research project in Bioinformatics. This project can be performed either at ITI or at another research institute in Egypt. Each research group consists of 4-6 students to solve a research question utilizing the Bioinformatics tools and techniques, for example:

a. Drug Design for different diseases: Hepatitis Virus C 'HCV', Breast Cancer, etc.

b. Biomarkers

c. Decision trees to predict responses to different treatments

d. Data Mining in Bioinformatics

e. Workflow engineering for Bioinformatics research protocols

The current Bioinformatics program is presented at the ITI Assuit branch. The students take the Bioinformatics courses, and these soon include new planed courses on cutting-edge technologies such as Cloud Computing. Eventually, the students can develop Bioinformatics applications that can be offered as "Software as a Service (SaaS)" via the Egyptian Cloud Computing Center of Excellence (EC3) in Assuit. EC3 is a pilot research center on cloud computing led by ITI.

\subsection{HCP Track - MoH/ITI Health Informatics Fellowship}

In 2009, the Ministry of Health (MoH)Egyptian Fellowship Board jointly with
ITI launched the first Egyptian Health Informatics Fellowship program. This program mainly aims at educating and training healthcare stakeholders affiliated to $\mathrm{MoH}$. However, healthcare practitioners, working in private and public healthcare organizations in Egypt and Arab region, are also eligible to join this program.

The curriculum of the program has been developed according to the IMIA recommendations on Education in BMHI [5]. Accordingly, the courses fulfill the learning outcomes for BMHI specialists. The MoH/ITI Health Informatics Fellowship is a 2-year part-time program (2 days per week). In this way, it fits with the tight schedule of healthcare practitioners.

The program comprises 14 courses in addition to the practicum. ITI offers the seven core courses in BMHI while $\mathrm{MoH}$ Fellowship Board provides the other seven courses. Most of the courses include both in-class lectures and field visits. The sequence of delivering these courses is as follows:

1) Basics of Information Technology "The Level of Internet and Computing Core Certification (IC3)", 2) Overview of Heath Informatics, 3) E-Collaboration in Health Care, 4) Health Information System and Electronic Medical Records, 5) Interoperability of Health Information, 6) Online Medical Resources and Research Engines, 7) Fundamentals of Research Design and Medical Statistics, 8) Evidence based health and Clinical Practice Guidelines, 9) Medical Coding and ICD10, 10) Picture Archiving And Communication Systems (PACS), 11) Bioinformatics, 12) Mobile Technology, 13) Project Management, 14) Change Management.

At the practicum phase, all students have to practice their knowledge and skills gained during the program in a form of either internships or graduation projects at $\mathrm{MoH}$ affiliated healthcare facilities.

\subsection{Additional BMHI Courses}

Starting from 2009, ITI offers "Computer Science and Biomedical Infor- matics" course for the pre-master students of the Faculty of Pharmacy-Alexandria University. Through this course, the students acquire the fundamentals of IT in addition to an overview of BMHI discipline with focusing mainly on the Bioinformatics domain. One of the activities in this course is the journal club in which the students explore the BMHI applications in pharmaceutical sciences. This course lasts for 14 weeks, as a two-hour lecture per week.

\section{ITI BMHI Research Projects}

The ITI Research \& Development (R\&D) Department has adopted an ambitious Innovation Strategy focusing on Science, Technology and Innovation (STI) capacity Building. Healthcare is one of the ITI focused innovation areas that also matches both worldwide innovation themes as well as MCIT strategies. Accordingly, ITI is able to attract international research projects funded by the European Union (EU).

Since 2006, ITI has attracted three BMHI research projects in knowledge management in healthcare, providing tele-consultation services for diagnosis/ treatment of infectious diseases for underserved regions in Egypt, and exploring the cultural and educational aspects of Nanoinformatics. The broad objectives of these projects are:

- Staying abreast of global trends as well as responding to national needs

- Facilitating academic exchange and cooperation in BMHI Networks of Excellence

- Establishing a dialogue on enhancing innovation competencies

- Supporting the establishment of the ITI BMHI centre of excellence

Table 3 highlights to which extent these objectives have been realized in each research project.

\subsection{Knowledge Management in Healthcare}

The Knowledge Management in Healthcare project started in 2006 in 
Table 3 ITI BMHI research projects and their realized objectives

\begin{tabular}{l|c|c|c|}
\hline & $\begin{array}{c}\text { Knowledge Management } \\
\text { in Healthcare }\end{array}$ & TeleMedic@Egypt & ACTION-Grid \\
\hline Relevancy to the global trends & $X X X$ & $X X X$ & $X X$ \\
Relevancy to the national needs & $X X X$ & $X X X$ & - \\
Facilitating academic exchange & $X X X$ & $X X$ & $X X X$ \\
Cooperation in BMHI Networks of & $X X$ & $X X X$ \\
Excellence & $X X$ & $X X X$ \\
$\begin{array}{l}\text { Establishing a dialogue on } \\
\text { enhancing innovation competencies }\end{array}$ & $X X$ & $X$ & FP7 \\
$\begin{array}{l}\text { Supporting the establishment of } \\
\text { the ITI BMHI centre of excellence }\end{array}$ & XX \\
Funding Scheme & IT/University of Leipzig & RDI \\
\hline
\end{tabular}

Legend (-) Not Applicable $\quad(X)$ Acceptable $\quad(X X)$ Moderate $\quad(X X X)$ High

collaboration with the Institute of Medical Informatics, Statistics and Epidemiology (IMISE), the University of Leipzig in Germany.

The objective of this project is to utilize the Three-Layer Graph-based Meta Model $\left(3 \mathrm{LGM}^{2}\right)$ tool, developed by IMISE, in modelling the Integrating Healthcare Enterprise (IHE) - Integration Profiles.

The main concept of the modelling process is mapping the IHE four-level model [10] to a compliant $3 \mathrm{LGM}^{2}$ model following these five steps:

1. The IHE Integration Profiles (the abstract representation of the realworld integration problems and solution scenarios) are modelled in the $3 \mathrm{LGM}^{2}$ domain layer (in which the healthcare enterprise functions and entity types are represented).

2. The IHE Actors (the abstract representation of the health information systems) are modelled in the $3 \mathrm{LGM}^{2}$ logical tool layer (in which the computer-based application components are represented).

3. The IHE Transactions (the abstract representation of the healthcare performed tasks) are modelled in the $3 \mathrm{LGM}^{2}$ domain layer as functions.

4. The healthcare communication messages, such as Health Level 7 (HL7) and Digital Imaging and Communication in Medicine (DICOM) messages are typically modelled in the $3 \mathrm{LGM}^{2}$ logical layer identifying the communication standard, event types, message types, and their combination, etc.

5. Finally, the suggested or implemented hardware components of the healthcare system, e.g., computers, servers, network components, etc. are modelled in the $3 \mathrm{LGM}^{2}$ Physical tool layer.

This project consisted of three phases:

- Phase 1 (Jun 2006 - Dec 2006): Modelling the radiology department workflow, in which the 3-layer model of the imaging department workflow was created [11].

- Phase 2 (Jan 2007 - Jul 2008): Modelling the hospital scheduled workflow, in which the 3-layer model of the IHE- scheduled workflow integration profile was created [12].

- Phase 3 (Oct 2009 - Feb 2010): Modelling the clinical documentation, in which 3-layer model of the IHE- Cross Enterprise Document Sharing (XDS) profile was created. The benefits of modelling the IHE integration profiles are threefold:

- Better understanding of the structure and dynamics of the IHE-inte- gration profiles. Eventually, this will ensure that the healthcare practitioners will share a common understanding of the IHE concepts.

- Precisely identifying the requirements of the system to support the healthcare organization.

- Enhancing systematic management of the hospital information systems with quality assessment of information processing.

\subsection{TeleMedic@Egypt Project}

Since 2009, ITI is the coordinator of the Telemedic@Egypt project funded by the Research, Development and Innovation Programme (RDI) [13]. RDI is a program of the Ministry of Higher Education and Scientific Research funded by the European Union (EU) (http:// www.rdi.eg.net). This project aims at providing teleconsultation services for diagnoses treatment of infectious diseases, like $\mathrm{HCV}$, for underserved regions in Egypt with maximum efficiency and cost effectiveness.

Throughout this project, ITI in partnership with Fraunhofer Institute for Biomedical Engineering IBMT (Germany), The Holding Company for Biological Products and VaccinesVACSERA (Egypt), University of Birmingham (UK), and Technical University of Crete (Greece) connect highlevel healthcare resources available in large cities with low-level healthcare facilities in underserved and remote regions. The project is operated in cooperation with stakeholders from MCIT and MoH. This project runs till July 2011.

The proposed scenario for providing Telemedicine services, such as a second opinion, remote case findings, and remote diagnosis \& therapy for the underserved regions in Egypt, is as follows:

- Use the TOPCARE Telemedicine platform, developed by Fraunhofer IBMT [14], in the Egyptian rural medical centres, mainly affiliated to $\mathrm{MoH}$, to obtain telemedicine support from experienced Egyptian health- 
care institutions such as VACSERA.

- The TOPCARE Telemedicine platform consists of: TOPCARE Telehealth Kiosk (at the rural medical centres), TOPCARE Telehealth Server and Telehealth Client for the remote expert (web-based).

- The Telehealth Kiosk will be directly used at the point-of-care when the patient is examined for infectious diseases.

- The Telehealth Kiosk is equipped with medical diagnostic devices such as: a microscope with a digital camera, blood pressure, weight scale, urine analyser, blood analyser, and optionally X-ray scanner in addition to a web cam for conducting a video conference and a printer for documentation.

- The diagnostic data from this equipment is directly stored in the kiosk.

- The doctor fills in a detailed description of the patient's status via a special template called Case Report Form (CRF), which is designed for a certain infection diseases.

- The CRF is sent by the kiosk to the expert together with the diagnostic data from the medical devices for remote evaluation and advice.

- The expert fills-in his treatment recommendations and sends them back to the TOPCARE Telehealth Kiosk.

- The patient's data is stored in a local database at the kiosk as well as in the central database on the TOPCARE Telehealth Server.

- Discussions between the remote experts and the on-site physicians can be conducted either in an online mode (via videoconference and/or utilizing the kiosk's screen) and an offline mode of the TOPCARE Telehealth Platform (via exchanging the CRFs).

The main outputs of this project could be summarized as follows:

- Customizing the TOPCARE Telehealth Kiosk System to serve the major infections diseases in Egypt, mainly Hepatitis.

- Implementing the kiosk in two medical centres located in two rural areas in Egypt, namely, Mahsma and Belbeis.
- Integrating the customized solution with the National Telemedicine Network (when activated).

- Developing a roadmap for the Telemedicine strategy and implementation in Egypt.

- Capacity building on telemedicine technologies and applications, starting with the staff of the medical centres.

\subsection{ACTION-Grid Project "Panel of Expert"}

The first author of this paper is a member of the Panel of Experts for the ACTION-Grid Project (http://www.actiongrid.eu/index.php? url=home). ACTION-Grid is a Specific International Cooperation Project on healthcare information systems based on Grid capabilities, BMI, and Nanoinformatics between Latin America, the Western Balkans, and the EU. This project was supported by the EU's Seventh Framework Programme (FP7)-ICT Theme. The project consortium consists of the coordinator at the Universidad Politecnica de Madrid (UPM) (Spain) in partnership with the Instituto de Salud Carlos III (Spain), Foundation for Research and Technology (Greece), Sociedad Italiana de Beneficencia en Buenos Aires (Argentina), Universidad de Talca (Chile), HealthGrid (France), Sveuciliste u Zagrebu, Medicinski Facultet (Croatia). ACTION-Grid started in June 2008 and finished in June 2010.

The main activities carried out by the authors in this project:

- Participation in the ACTION-Grid survey to obtain insight into the research target areas by contacting and distributing the survey among about 43 candidates from Egypt, Sudan, Libya, Tunisia, Algeria and Morocco.

- Participation in developing and writing the ACTION-Grid white paper by:

1. Identifying the list of hot topics for the future development of the BMI domains,
2. Completing the ACTION-Grid experts' questionnaire exploring the new trends of medicine: BMHI technologies, tools and techniques, search challenges, and its impact on education,

3. Authoring the Cultural and Educational Aspects section of the ACTION-Grid white paper, particularly, the educational and research programs for Nanoinformatics [15]. The main topics discussed on Nanomedicine and Nanoinformatics educational aspects are: the definition of the Nanoinformatics field, the relationship of Nanobiotechnology to Nanomedicine, the current research and education programs in Nanomedicine, the Nano-medicine education of healthcare professionals as well as the public, and, finally, the recommendations on Nanoinformatics education and training programs in light of the IMIA recommendations [5].

In addition, the ITI BMHI staff has been working with the biomedical informatics group from the Universidad Politecnica de Madrid in distributed computing experiments related to medical and bioinformatics topics, and BMI education and collaborative research over the Internet. They are currently being expanded in the framework of the AFRICA Build project, funded by the European Commission, which is planned for the period 2011-2014 at the time of writing this paper. ITI will be one of the main partners in this coordination action.

\subsection{BMHI Research Internship Program for the University of Leipzig Students}

This internship program took place (from October 2009 till February 2010) at the ITI premises in collaboration with the IMISE, University of Leipzig. The authors of this paper provided the required knowledge on IHE concepts to one of 
the IMISE students who participated in the third phase of the research project entitled "Modeling the clinical documentation" as described in section 5.1.

\section{Conclusion}

Evolving from the MCIT strategy to enrich ICT sectors with highly qualified calibers, ITI aims at spreading BMHI knowledge and practice in different Egyptian governorates. This is achieved through establishing partnerships with well-known universities, namely, OHSU in the USA and the University of Leipzig in Germany, as well as the Egyptian Ministry of Health. Accordingly, ITI offers BMHI education, training, and research to all types of healthcare stakeholders that eventually fulfill the needs of the healthcare sectors not only within Egypt but also along the Arabic Region.

The learning objectives of the BMHI training programs are framed within the context of the four specialization tracks: Healthcare management (HCM) Track, Biomedical Informatics Research (BMIR) Track, Bioinformatics Professional (BIP) Track, and Healthcare Professional (HCP) Track. Accordingly, the graduates' profile covers a wide-range of BMHI specializations: clinical systems analysts, BMHI teaching and research assistants, health informaticians and informatics training directors.

Furthermore, the ITI BMHI research projects tackle a wide-range of current challenges in this field such as knowledge management in healthcare, telemedicine applications, and designing the Nanoinformatics educational programs. In parallel, ITI is introducing the research results and the outputs of these projects to the healthcare stakeholder in Egypt.

The future trend of this work is to offer all BMHI training programs through eLearning environment. In this way, ITI will overcome not only geographical barriers and the tight time schedule of healthcare practitioners, but also the shortage of distinguished BMHI professionals who give these courses. Additionally, these BMHI programs will be accredited to maintain the highest education standards and appropriate competencies.

Finally, ITI will continue to positively contribute to the development of the BMHI discipline in Egypt for offering better healthcare services. This is being achieved through the ITI integrated initiatives for Continuing Education \& Professional Training, Healthcare Community Service \& Consultation, and Research \& Development.

\section{References}

1. Shortliffe EH, Cimino JJ. Biomedical Informatics: Computer Applications in Healthcare and Biomedicine 3rdEdition. New York, USA: Springer; 2006

2. Kay M, van Andel MO, Klint K, Tristram C. Building Foundations for eHealth: Progress of Member States: report of the Global Observatory for eHealth. Switzerland: WHO Press; 2006. Available from: www.who.int/goe/publications/ bf FINAL.pdf.

3. Ministry of Communications and Information Technology-Arab Republic of Egypt. Ministry of Communications and Information Technology: Yearbook 2006. Egypt: Ministry of Communications and Information Technology; 2006. Available from: http://www.mcit.gov.eg/Upcont/Documents/ MCITYEARBOOK2006.pdf.

4. Lorenzi NM. Towards IMIA 2015 - the IMIA Strategic Plan. IMIA Yearbook 2007: Biomedical Informatics for Sustainable Health Systems. 2007:1-5.

5. Mantas J, Ammenwerth E, Demiris G, Hasman A, Haux R, Hersh W, et al. IMIA Recommendations on Education Task Force. Recommendations of the International Medical Informatics Association (IMIA) on Education in Biomedical and Health Informatics. First Revision. Methods InfMed 2010 Jan 7;49(2):105-20.

6. Al-Shorbaji N. Technical Paper: EMR Regional Committee Resolutions on Health Informatics and Telematics. World Health Organization - Regional Office for the Eastern Mediterranean: E-Health in the Eastern Mediterranean [internet]. 2001 [cited 2010 Dec 8]. Available from: http://www.emro.who.int/ his/ehealth/rcresolutions-rc48.htm.

7. Kay M, Santos J, Takane M. Atlas eHealth country profiles: based on the findings of the second global survey on eHealth. (Global Observatory for eHealth Series, 1). Switzerland: WHO Press; 2011. Available from: whqlibdoc.who.int/publications/2011/ 9789241564168_eng.pdf.

8. Medical and Bioinformatics Master Program (MBIMP) [Internet]. 2008 [cited 2010 Dec 8] Available from: http://mbimp.org/index.php.

9. Sharaf Eldin A, Moustakis VS. MIMP: Introducing Postgraduate Education in Medical Informatics in Egypt. Nuove Tecnologie In Medicina: Applicazioni Informatiche E Telematiche In Medicina [internet]. 2006 [cited 2010 Dec 8]; 6(3): 51-53. Available from: http://www.sirse.net/nav/Editoria/ Nuove_Tecnologie_in_Medicina/ ANNO_6_N.322006/E_LEARNING/ 96573.html.

10. Anzbock R, Dustdar S. Modeling and implementing medical Web services. Data \& Knowledge Engineering 2005; 55:203-36.

11. Hussein R. Using the $3 \mathrm{LGM}^{2}$ Tool for Modeling the Imaging Department Workflow. In: El-Hadidi M, editor. ICICT 2006. Proceeding of the $4^{\text {th }}$ International Conference on Information and Communications Technology; 2006 Dec 10-12; Cairo, Egypt. Cairo: Publication of Information Technology Institute (ITI), IEEE catalog number: 06EX1457; 2006. p. 543-53.

12. Hussein R, Winter A. Towards More Integrated Implementation of Healthcare Information Systems Using the $3 \mathrm{LGM}^{2}$ for modeling the IHE-Scheduled Workflow Integration Profile. CBMS 2008. Proceedings of the $21^{\text {st }}$ IEEE International Symposium on ComputerBased Medical Systems; 2008 Jun 17-19; Jyväskylä, Finland. 2008. p. 650-2

13. Research, Development and Innovation Programme (RDI), EU-Egypt Innovation Fund (EEIF). Projects' catalogue [Internet]. 2009 [cited 2010 Dec 8]. Available from: http://www.rdi.eg.net/ D o c u m ent Library/Document s/ projects_catalogue.pdf.

14. Millan J, Park SE, Kiefer S, Meyer JU.TOPCAREImplementation of a telematic homecare platform in cooperative health care provider networks. 24th Annual Conference and the Annual Fall Meeting of the Biomedical Engineering Society. Proceeding of the Second Joint EMBS/BMES Conference; 2002; Houston, USA. Engineering in Medicine an Biology; 2002. P. 1-42. Available from: http:// i e e explor e. i e e e.org/x p l/ freeabs all.jsp?reload=true \&arnumber $=1053068$.

15. ACTION-Grid Consortium. The ACTION-Grid White Paper: Linking Biomedical Informatics, Grid Computing and Nanomedicine [internet]. 2010 [cited 2010 Dec 8]. Available from: http:// www.action-grid.eu/documents/ACTIONGrid\%20White\%20Paper.pdf.

Correspondence to:

Rada Hussein, PhD

Deputy for Research and Development (R\&D)

Information Technology Institute (ITI)

Ministry of Communications and Information Technology (MCIT)

Smart Village, B 148, 28 Km Cairo-Alex Desert Road

Cairo, Egypt, PO Box 12577

Tel: +20235355590

Fax: +20235370770

E-mail: rahussein@mcit.gov.eg 